\title{
DESEMPENHO DO TRATOR AGRICOLA NO MANEJO DA CULTURA DE COBERTURA E PRESSÃO DE INFLAÇÃO DO PNEU DA SEMEADORA
}

\author{
JORGE W. CORTEZ ${ }^{1}$, CARLOS E. A. FURLANI ${ }^{2}$, GUSTAVO P. VIGNA ${ }^{3}$, \\ EDINAN A. BORSATTO ${ }^{4}$, ROUVERSON P. DA SILVA ${ }^{5}$
}

\begin{abstract}
RESUMO: O adequado manejo de culturas de cobertura no plantio direto tem-se mostrado excelente alternativa para melhorar as condições de semeadura. O objetivo do presente trabalho foi avaliar o desempenho do trator agrícola no manejo dos restos culturais do sorgo (rolo-faca e triturador de palhas) e a pressão de inflação $(525 \mathrm{e} 385 \mathrm{kPa})$ do pneu da semeadora-adubadora, no estabelecimento da cultura do milho em plantio direto. $\mathrm{O}$ experimento foi conduzido na UNESP Jaboticabal, em delineamento de blocos ao acaso, com parcela subdividida, e os tratamentos consistiram nos manejos da cultura de cobertura do solo e pressões de inflação do pneu da semeadora, com quatro repetições. Foram mensurados nas máquinas: velocidade de deslocamento, capacidade de campo, consumo de combustível e patinhagem do trator; no solo e nas plantas, foi acrescido o tratamento de manejo com herbicida: cobertura inicial, número de dias para emergência das plântulas, população inicial e final de plantas, distribuição longitudinal e produtividade de grãos. No manejo da palhada da cultura do sorgo, o rolo-faca proporcionou maior capacidade de campo e menores consumos de combustível. Os tratamentos manejos e pressão não interferiram na cobertura do solo, no número de dias para emergência do milho e na distribuição longitudinal.
\end{abstract}

PALAVRAS-CHAVE: patinhagem, plantio direto, Zea mays.

\section{AGRICULTURAL TRACTOR PERFORMANCE IN THE MANAGEMENT OF COVERAGE CROP AND TIRE INFLATION PRESURE OF SOWING MACHINE}

\begin{abstract}
The appropriate management of coverage crops in no tillage has been shown as an excellent alternative to improve seedling conditions. The aim of the present study was to evaluate the performance of the agricultural tractor in management (knife-rolls and straw shopper) of the sorghum residues and the tire inflation pressure $(525$ and $385 \mathrm{kPa})$ of sowing-fertilizer machine for establishing corn crop in no tillage. The experiment was done at the São Paulo State University in the city of Jaboticabal - SP, Brazil, with delineation in randomized blocks with split plot, and the treatments were composed by the management of coverage soil crop and tire inflation pressures of sowing with four repetitions. It was measured in the machines: displacement speed, field capacity, fuel consumption, tractor slippage; on the soil and on the plants; initial soil coverage, number of days for seedling, initial and final population of plants, longitudinal distribution and productivity. In the sorghum mulch management, the rotating knife provided higher field capacity and lower fuel consumption. The management and pressures did not interfere in soil coverage, number of days for corn seedling and longitudinal distribution.
\end{abstract}

KEYWORDS: slippage, no tillage, Zea mays.

\footnotetext{
${ }^{1}$ Eng ${ }^{\mathrm{o}}$ Agrônomo, Doutorando (Produção Vegetal), Departamento de Engenharia Rural, UNESP, Jaboticabal - SP, jorge.cortez@yahoo.com.br. Bolsista CAPES.

${ }^{2}$ Eng $^{0}$ Agrônomo, Prof. Adjunto, Departamento de Engenharia Rural, UNESP, Jaboticabal - SP. Bolsista de Produtividade CNPq.

${ }^{3}$ Aluno de graduação em Agronomia, UNESP, Jaboticabal - SP.

${ }^{4}$ Eng ํ Agrônomo, Doutorando (Ciência do Solo), Departamento de Engenharia Rural, UNESP, Jaboticabal - SP.

${ }^{5}$ Eng ${ }^{\circ}$ Agrícola, Prof. Doutor, Departamento de Engenharia Rural, UNESP, Jaboticabal - SP. Bolsista de Produtividade CNPq.

Recebido pelo Conselho Editorial em: 10-10-2007
}

Aprovado pelo Conselho Editorial em: 20-9-2008

Eng. Agríc., Jaboticabal, v.29, n.1, p.72-80, jan./mar.2009 


\section{INTRODUÇÃO}

O manejo da cultura de cobertura visa à realização de operações de preparo conservacionista, tendo como finalidade a redução do comprimento das palhas, principalmente para a utilização do plantio direto (YAMAOKA, 1984). Tal procedimento permite melhores condições de desempenho de equipamentos de preparo do solo, ou proporcionar o dessecamento e a morte dessa vegetação, formando o "mulch" sobre a superfície para que se efetue a semeadura (CASÃO JÚNIOR et al., 1989).

Os sistemas conservacionistas preconizam manter a superfície do solo coberta o máximo de tempo sem ocorrer a exposição do solo à ação do ambiente; essa cobertura deve estar distribuída o mais uniformemente possível para permitir proteção homogênea e possibilitar condições iguais de semeadura em toda a área (FURLANI et al., 2003). O plantio direto depende da produção de biomassa formada por resíduos de colheita, adubos verdes ou plantas daninhas (MERTEN \& FERNANDES, 1998), assim as culturas de cobertura devem permanecer na superfície do solo para proteção, e as plantas daninhas devem ser controladas com o uso de herbicidas.

As culturas de cobertura podem ser manejadas por diferentes equipamentos, no entanto cada um deles pode influenciar de forma direta na velocidade de decomposição da palha, em virtude da menor ou maior fragmentação do material (GAMERO et al., 1997). Para o plantio direto, os equipamentos mais recomendados para o manejo das culturas de cobertura ou adubos verdes são o rolo-faca, as roçadoras e os trituradores de palha tratorizados (PRADO et al., 2002).

O triturador de palhas tem grande eficiência na trituração da parte aérea de plantas com diferentes hábitos de crescimento e idade; os restos vegetais triturados permanecem sobre a superfície do solo para posterior decomposição ou podem ser incorporados (VIEIRA \& REIS, 2001). Outro equipamento, o rolo-faca, promove o acamamento ou até mesmo o corte das restevas e de plantas, pela criação de uma situação estressante às mesmas, facilitando a incorporação de massa verde, além de viabilizar o cultivo mínimo e o plantio direto.

Os herbicidas utilizados para manejar as plantas daninhas antes da semeadura da cultura para formar palhada são importantes no plantio direto, destacando-se os dessecantes sem efeito residual, como, por exemplo, o glyphosate e o paraquat (CARVALHO et al., 2003).

Comparando diferentes métodos de manejo da vegetação espontânea, concluíram que, em se tratando de consumo de combustível e tempo, o manejo com herbicida foi o que apresentou os melhores resultados por apresentar a maior largura da faixa de trabalho $(12 \mathrm{~m})$, em comparação com rolo-faca $(2 \mathrm{~m})$, roçadora $(1,5 \mathrm{~m})$ e triturador de palhas $(2,3 \mathrm{~m})$; desse modo, o uso desses equipamentos de manejo mecânico em área de pousio promove a homogeneização da cobertura do solo, beneficiando a pulverização (MARQUES et al., 1999).

Pressupõe-se que os equipamentos de manejo mecânico da cultura de cobertura, juntamente com as pressões de inflação do pneu da semeadora não afetam o desenvolvimento e a produtividade da cultura do milho.

Assim, o objetivo do presente trabalho foi avaliar o desempenho do conjunto trator-implementos de manejo (rolo-faca e triturador de palhas) da cultura de cobertura (sorgo) e pressões de inflação do pneu da semeadora-adubadora, no estabelecimento da cultura do milho. Para a avaliação dos componentes de solo e planta, foi acrescido o tratamento herbicida.

\section{MATERIAL E MÉTODOS}

O experimento foi conduzido na área experimental do Departamento de Engenharia Rural da Universidade Estadual Paulista, Câmpus de Jaboticabal, São Paulo, situada na latitude $21^{\circ} 14^{\prime}$ S e longitude $48^{\circ} 17^{\prime} \mathrm{W}$, com altitude média de $559 \mathrm{~m}$. O clima da região é Aw, com temperatura média de $23,4^{\circ} \mathrm{C}$, precipitação de $48,2 \mathrm{~mm}$, umidade relativa de $75 \%$ e pressão atmosférica de $942,4 \mathrm{kPa}$. 
O solo da área experimental, cuja declividade era de 4\%, foi classificado como Latossolo Vermelho eutroférrico típico, relevo suave ondulado (EMBRAPA, 1999).

A cultura de cobertura utilizada foi o híbrido precoce de sorgo (Pionner 85G79), sendo dessecado com glifosate ( 5 litros do produto por hectare e volume de calda de $280 \mathrm{~L} \mathrm{ha}^{-1}$ ) no tratamento com herbicida. As parcelas sorteadas para receber o manejo mecânico com triturador de palhas e com o rolo-faca receberam uma aplicação de glifosate, devido à presença de capim-amargoso (Digitaria insularis), com a mesma dose e para que não ocorresse a rebrota do sorgo.

Na semeadura do milho (Zea mays L.), foi utilizado o híbrido DKB-390 da DEKALB (híbrido simples), mantendo-se população aproximada de 60 mil plantas ha ${ }^{-1}$, com espaçamento de $0,90 \mathrm{~m}$. Também foram utilizados $320 \mathrm{~kg} \mathrm{ha}^{-1}$ da fórmula 4-20-20 (N-P-K) na semeadura e $90 \mathrm{~kg} \mathrm{ha}^{-1} \mathrm{de} \mathrm{N}$, na forma de ureia na cobertura, além da realização de duas pulverizações para o controle de lagarta do cartucho (Spodoptera frugiperda), sendo realizada com os inseticidas lambda-cialotrina $\left(0,2 \mathrm{~L} \mathrm{ha}^{-1}\right)$ e lefenurom $\left(0,3 \mathrm{~L} \mathrm{ha}^{-1}\right), 15$ dias após a emergência.

Foi utilizado, no manejo e na semeadura, o trator VALTRA, modelo BM100, 4x2 TDA (tração dianteira auxiliar) com 73,6 kW (100 cv) de potência no motor; equipado com sistema de aquisição de dados (micrologger CR23X), da marca CAMPBELL SCIENTIFIC, equipado com placa multiplexadora de 8 canais, modelo SDM-INT8 SN:2094, programado para obter uma leitura por segundo.

$\mathrm{Na}$ semeadura do milho, foi utilizada a semeadora-adubadora de precisão, da marca Marchesan, modelo PST Plus, equipada com quatro linhas de semeadura, espaçadas de 0,9 m, capacidade de $40 \mathrm{~kg}$ para sementes e $700 \mathrm{~kg}$ de adubo, com peso líquido aproximado de $2.212 \mathrm{~kg}$ e largura útil de $3,6 \mathrm{~m}$.

O rolo-faca foi construído pelo LAMMA (Laboratório de Máquinas e Mecanização Agrícola), com 13 facas dispostas em sua periferia, largura de corte de $2,1 \mathrm{~m}$ e massa com lastro de $720 \mathrm{~kg}$, haste sulcadora de adubo com as seguintes características: $2,7 \mathrm{~cm}$ de espessura da ponteira; $1,0 \mathrm{~cm}$ de espessura da haste, distância do disco de corte à haste de $12 \mathrm{~cm}$, relação entre altura e comprimento da ponteira (H/L) de 1,06 e ângulo de ataque de $20^{\circ}$; disco duplo desencontrado de $16 "(40,6 \mathrm{~cm})$ para deposição da semente.

O triturador de palhas utilizado é da marca Jumil 2300 montado, com rotor horizontal de $61 \mathrm{~cm}$, largura de corte de 2,3 m, 32 pares de facas curvas oscilantes e reversíveis, sistema de regulagem de altura de corte e massa de $735 \mathrm{~kg}$.

O pulverizador é da marca Jacto - Condor, modelo M12/75, série 9300, montado, com tanque para capacidade de $600 \mathrm{~L}$ de calda, com massa de $255 \mathrm{~kg}$, barra de $12 \mathrm{~m}$, equipada com bicos tipo leque (XR Teejet - 110.02VS) para aplicação de herbicidas.

O experimento contou com 24 parcelas de $65 \mathrm{~m}$ de comprimento por $4 \mathrm{~m}$ de largura, com intervalo entre parcelas de $15 \mathrm{~m}$ para realização de manobras e estabilização dos equipamentos. Os tratamentos consistiram em três manejos de cobertura do solo e duas pressões de inflação da roda acionadora da semeadora, com quatro repetições para a análise dos dados de solo e de planta. Os fatores de manejos foram: $\mathrm{M}_{1}$ - rolo-faca; $\mathrm{M}_{2}$ - triturador de palhas, e $\mathrm{M}_{3}$ - herbicida, combinados com duas pressões de inflação: $\mathrm{P}_{1}-525 \mathrm{kPa}$ e $\mathrm{P}_{2}-385 \mathrm{kPa}$. O delineamento experimental foi em blocos casualizados com parcela subdividida ( $3 \times 2$ ). Para os dados de desempenho do trator durante o manejo da cultura de cobertura, foi utilizado o delineamento inteiramente casualizado, com dois tratamentos (rolo-faca e triturador de palhas), com dez repetições, pois não permitiu o acoplamento do pulverizador no trator de teste instrumentado.

Para a medição da velocidade real de deslocamento, foi utilizada unidade de radar (modelo RVS II), localizado na lateral esquerda do trator. A capacidade de campo efetiva foi determinada com base na largura de trabalho do equipamento de manejo e da velocidade real de deslocamento do conjunto. 
Para medir o consumo de combustível, foi utilizado um protótipo desenvolvido por LOPES et al. (2003). Os consumos de combustível horário, operacional e ponderal foram calculados seguindo as eqs.(1), (2) e (3):

$$
\mathrm{Chv}=\frac{\mathrm{C} 3,6}{\mathrm{t}}
$$

em que,

Chv - consumo horário volumétrico, $\mathrm{L} \mathrm{h}^{-1}$;

C- volume consumido, $\mathrm{mL}$, e

$\mathrm{t}$ - tempo de percurso na subparcela, $\mathrm{s}$.

$$
\mathrm{CO}=\frac{\mathrm{Chv}}{\mathrm{CCE}}
$$

em que,

$\mathrm{CO}$ - consumo operacional, $\mathrm{L} \mathrm{ha}^{-1}$, e

CCE - capacidade de campo efetiva, ha $\mathrm{h}^{-1}$.

$$
\text { Chp }=\frac{\text { Chv DC }}{1000}
$$

em que,

Chp - consumo horário ponderal, $\mathrm{kg} \mathrm{h}^{-1}, \mathrm{e}$

DC - densidade do combustível $\left(\mathrm{g} \mathrm{L}^{-1}\right)$, obtida por meio da equação $\mathrm{DC}=(-0,697 \mathrm{~T})+851,04$, em que, T - temperatura do combustível em ${ }^{\circ} \mathrm{C}$, apresentada por GROTTA (2003).

Para determinar a patinhagem dos rodados, utilizou-se de sensores modelo GIDP-60-12 v em cada uma das rodas e obteve-se a média dos giros para o trator, sem e com carga. Para o cálculo da patinhagem, os dados emitidos na forma de sinal ou pulsos foram armazenados no sistema de aquisição de dados e depois procederam-se aos cálculos pela eq.(4):

$$
\mathrm{P}=\left(1-\frac{\mathrm{NPS}}{\mathrm{NPC}}\right) 100
$$

em que,

$\mathrm{P}$ - patinhagem, \%;

NPC - número de pulsos da roda, operando com carga na barra de tração, e

NPS - número de pulsos da roda, operando sem carga na barra de tração.

No solo, foi determinada a percentagem de cobertura inicial do solo por resíduos vegetais após o manejo pelo método de LAFLEN et al. (1981). Foram realizadas duas leituras nas diagonais das parcelas e, posteriormente, obtidas às médias.

Com relação as plântulas de milho, determinou-se o número médio de dias para a emergência por meio de contagens diárias, desde a primeira planta emergida até a estabilização do número. Para as contagens, utilizaram-se, em cada parcela, duas fileiras centrais de semeadura com $2 \mathrm{~m}$ de comprimento. A partir das contagens, expressou-se esse parâmetro de acordo com EDMOND \& DRAPALA (1958).

A determinação da população inicial de plantas de milho foi realizada, pela contagem de duas fileiras, cada uma com $2 \mathrm{~m}$ de comprimento. Esses valores foram, posteriormente, transformados em número de plantas por hectare. A percentagem de espaçamentos aceitáveis foi calculada considerando todos os espaçamentos entre plantas de 0,5 e 1,5 vez o espaçamento médio esperado (EM). Os valores obtidos fora desse limite foram considerados como falha de semeadura (acima de 1,5 vez EM) ou duplos (abaixo de 0,5 vez EM), conforme ABNT (1989). 
A produtividade de grãos foi obtida pela coleta manual em duas fileiras de $2 \mathrm{~m}$ por parcela. As espigas foram despalhadas manualmente e debulhadas em máquina estacionária, sendo pesados, separadamente, palha, sabugo e grãos, sendo, posteriormente, o peso dos grãos corrigido para $13 \%$.

Os dados obtidos foram tabulados e submetidos à análise de variância, e quando o valor do teste $\mathrm{F}$ foi significativo a $5 \%$ de probabilidade, foi realizado o teste de Tukey para a comparação de médias.

\section{RESULTADOS E DISCUSSÃO}

$\mathrm{Na}$ Tabela 1, são apresentados os resultados da síntese da análise de variância para os parâmetros de velocidade e de capacidade de campo efetiva. Observa-se que o manejo com rolo-faca apresentou a possibilidade de trabalhar com maiores velocidades. Isso ocorreu em função da marcha de trabalho e maior facilidade de rolagem da vegetação. O fato de o rolo-faca rolar sobre o solo permite trabalhar a maiores velocidades (GERLACH, 2005), visto que não há a necessidade de picar a cobertura vegetal, mas apenas amassá-la, ou seja, promover a interrupção da seiva pelos vasos condutores da planta.

O triturador de palhas, no entanto, necessita de maior potência pela necessidade de picar a cobertura vegetal. Observou-se diferença de $28 \%$ na velocidade de deslocamento entre esses equipamentos. O simples fato de o triturador passar sobre a cultura de cobertura não garante o corte e a uniformidade de distribuição da palhada; assim, é necessária menor velocidade para a obtenção da melhor qualidade operacional. Diferentemente desses resultados, CHAHIM FILHO (2005) concluiu que o fator equipamentos de manejo da cobertura vegetal não influenciou na velocidade de deslocamento, o que corrobora os resultados de MONTEIRO FILHO (2005), que observou a pequena variação de velocidade ocorrida durante a execução do experimento e não detectou influência dos fatores de manejo na capacidade de campo.

A capacidade de campo operacional é função da velocidade de deslocamento e da largura de trabalho. Observou-se que ocorreu diferença de $25,2 \%$ entre o rolo-faca e o triturador de palhas, inferior ao encontrado para a velocidade, fato devido à maior largura de trabalho do triturador em relação ao rolo-faca. $\mathrm{O}$ fato da menor demanda de potência observada para o rolo-faca, permite que se tenha a possibilidade de trabalhar com equipamentos de maior largura de trabalho, o que permite trabalhar maiores áreas em menor tempo.

TABELA 1. Síntese de análise de variância para velocidade de deslocamento e capacidade de campo operacional (CCO) no momento do manejo da cultura de cobertura. Variance analysis synthesis for displacement speed and operational field capacity $(\mathrm{CCO})$ at the moment of management of coverage crop.

\begin{tabular}{lcc}
\hline Fatores & Velocidade $\left(\mathrm{km} \mathrm{h}^{-1}\right)$ & $\mathrm{CCO}\left(\mathrm{ha} \mathrm{h}^{-1}\right)$ \\
\hline Manejos (M) & & \\
Rolo-faca & $5,3 \mathrm{~A}$ & $1,1 \mathrm{~A}$ \\
Triturador & $3,6 \mathrm{~B}$ & $0,8 \mathrm{~B}$ \\
\hline Teste F & $177,4^{* *}$ & $103,9 * *$ \\
$\mathrm{M}$ & 4,4 & 1,0 \\
\hline Média & 0,1 & 0,2 \\
Erro Médio & 6,4 & 6,4 \\
\hline C.V. & &
\end{tabular}

Médias seguidas de mesma letra maiúscula na coluna não diferem entre si, pelo teste de Tukey, a 5\% de probabilidade. C.V.: coeficiente de variação. **significativo a $\mathrm{P}<0,01$.

Na Tabela 2, podem-se observar os dados de consumo de combustível e de patinhagem do trator na operação de manejo. Para o consumo horário de combustível (Chv), consumo operacional (CO) e consumo ponderal (Chp), observa-se que o rolo-faca apresentou sempre o menor consumo, 
sendo as diferenças de $6,7 \%, 31,0 \%$ e $7,2 \%$, respectivamente. A grande diferença observada para o consumo operacional deve-se à variação da CCO (Tabela 1).

O fator velocidade foi avaliado por MARQUES et al. (1999) e verificaram que os diferentes métodos de manejo da vegetação espontânea apresentam maior consumo de combustível (rolo-faca, roçadora e triturador de palhas) se comparados ao sistema de manejo com herbicida (pulverização), que permite maior velocidade de deslocamento.

A patinhagem do trator (Tabela 2) não apresentou diferença em relação aos manejos; assim, pode-se atribuir o valor da média de 5,0\% para a patinhagem traseira e de $16,5 \%$ para a dianteira.

TABELA 2. Síntese de análise de variância para consumo horário volumétrico (Chv), consumo operacional (CO), consumo horário ponderal (Chp), patinhagem traseira (\%) e patinhagem dianteira (\%) no momento do manejo da cobertura vegetal. Variance analysis synthesis for volumetric hour consumption (Chv), operational consumption (CO), ponderal hour consumption (Chp), rear deviation (\%) and front deviation $(\%)$ at the moment of the vegetal coverage management.

\begin{tabular}{lccccc}
\hline Fatores & $\begin{array}{c}\mathrm{Chv} \\
\left(\mathrm{L} \mathrm{h}^{-1}\right)\end{array}$ & $\begin{array}{c}\mathrm{CO} \\
\left(\mathrm{L} \mathrm{ha}^{-1}\right)\end{array}$ & $\begin{array}{c}\mathrm{Chp} \\
\left(\mathrm{kg} \mathrm{h}^{-1}\right)\end{array}$ & $\begin{array}{c}\text { Patinhagem } \\
\text { Traseira (\%) }\end{array}$ & $\begin{array}{c}\text { Patinhagem } \\
\text { Dianteira (\%) }\end{array}$ \\
\hline $\begin{array}{l}\text { Manejos (M) } \\
\text { Rolo-faca }\end{array}$ & $5,5 \mathrm{~B}$ & $5,0 \mathrm{~B}$ & $4,7 \mathrm{~B}$ & $5,8 \mathrm{~A}$ & $16,5 \mathrm{~A}$ \\
Triturador & $5,9 \mathrm{~A}$ & $7,2 \mathrm{~A}$ & $5,1 \mathrm{~A}$ & $4,1 \mathrm{~A}$ & $16,4 \mathrm{~A}$ \\
\hline Teste F & & & & & \\
M & $5,6^{* *}$ & $68,9^{* *}$ & $6,7^{* *}$ & $1,4^{\mathrm{NS}}$ & $0,00^{\mathrm{NS}}$ \\
\hline Média & 5,7 & 6,1 & 4,9 & 5,0 & 16,4 \\
Erro da Média & 0,1 & 0,2 & 0,1 & 1,0 & 1,6 \\
\hline C.V. & 6,6 & 9,8 & 6,5 & 64,1 & 31,7 \\
\hline Mér.
\end{tabular}

Médias seguidas de mesma letra maiúscula na coluna não diferem entre si, pelo teste de Tukey, a 5\% de probabilidade. C.V.: coeficiente de variação. ${ }^{* *}$ significativo a $\mathrm{P}<0,01 .{ }^{\text {ns }}$ não significativo.

Na Tabela 3, são apresentados os estandes iniciais e finais e a produtividade do milho em função dos manejos e das pressões de inflação.

TABELA 3. Síntese da análise de variância para estande inicial, estande final e produtividade após a semeadura do milho. Variance analysis synthesis for initial stand, final stand and productivity after corn sowing.

\begin{tabular}{lccc}
\hline Fatores & $\begin{array}{c}\text { Estande Inicial } \\
\left(\text { plantas ha }^{-1}\right)\end{array}$ & $\begin{array}{c}\text { Estande Final } \\
\left(\text { plantas ha }^{-1}\right)\end{array}$ & $\begin{array}{c}\text { Produtividade } \\
\left(\mathrm{kg} \mathrm{ha}^{-1}\right)\end{array}$ \\
\hline Manejos (M) & & & \\
Rolo-Faca & $75.000,0 \mathrm{~A}$ & $68.402,7 \mathrm{~A}$ & $9.477,5 \mathrm{~A}$ \\
Triturador & $75.694,0 \mathrm{~A}$ & $74.652,8 \mathrm{~A}$ & $10.064,1 \mathrm{~A}$ \\
Herbicida & $70.138,9 \mathrm{~A}$ & $70.138,7 \mathrm{~A}$ & $9.729,2 \mathrm{~A}$ \\
\hline Pressões $(\mathrm{P})$ & & & \\
$525 \mathrm{kPa}$ & $74.537,0 \mathrm{~A}$ & $74.305,5 \mathrm{~A}$ & $10.136,6 \mathrm{~A}$ \\
$385 \mathrm{kPa}$ & $72.685,0 \mathrm{~A}$ & $67.824,1 \mathrm{~B}$ & $9.377,3 \mathrm{~B}$ \\
\hline Teste F & $2,9^{\mathrm{ns}}$ & & 0,4 \\
M & $3,4^{\mathrm{ns}}$ & $2,5^{\mathrm{ns}}$ & $5,3 *$ \\
P & $1,5^{\mathrm{ns}}$ & $11,9 * *$ & $0,1^{\mathrm{ns}}$ \\
MxP & 6,8 & $1,2^{\mathrm{ns}}$ & 14,3 \\
\hline C.V. Manejo & 3,3 & 8,0 & 8,2 \\
C.V. Pressão & 6,5 & \\
\hline
\end{tabular}

Médias seguidas de mesma letra maiúscula na coluna não diferem entre si, pelo teste de Tukey, a $5 \%$ de probabilidade. C.V.: coeficiente de variação $(\%)$. **significativo a $\mathrm{P}<0,01 .{ }^{\text {ns }}$ não significativo. *significativo a $\mathrm{P}<0,05$. 
Somente o estande final e a produtividade foram afetados pelas pressões de inflação dos pneus da semeadora. $\mathrm{O}$ estande final foi maior na pressão de $525 \mathrm{kPa}$, o que ocasionou a maior produtividade neste tratamento.

A cobertura do solo e o número de dias para emergência das plântulas (Tabela 4) não foram afetados pelos fatores, indicando que se pode optar por qualquer manejo com relação à cobertura e ao número de dias para emergência. Os resultados da cobertura do solo apresentados pelos manejos não indicaram diferença, discordando de GAMERO et al. (1997), que afirmaram que o manejo com rolo-faca proporciona maior percentagem de cobertura do solo, comparado ao manejo com triturador de palhas, após 75 dias do manejo. Desse modo, a cobertura deixada inteira no solo (rolofaca) tem maior período de decomposição do que quando triturada. REIS et al. (2007) verificaram que até 70 dias após o manejo com rolo-faca, triturador e herbicida não há diferença na quantidade de material depositado no solo; no entanto, a partir de 97 dias após o manejo, o triturador apresentou a menor quantidade de resíduos, e aos 125 dias o rolo-faca e o triturador foram menores do que o tratamento com herbicida.

TABELA 4. Síntese da análise de variância para a cobertura do solo após o manejo e número de dias para a emergência de plântulas de milho após a semeadura. Variance analysis synthesis for soil coverage after management and number of days for corn seedling after sowing.

\begin{tabular}{lcc}
\hline Fatores & Cobertura do Solo (\%) & Número de Dias para Emergência \\
\hline Manejos (M) & $73,0 \mathrm{~A}$ & $4,3 \mathrm{~A}$ \\
Rolo-faca & $77,0 \mathrm{~A}$ & $4,4 \mathrm{~A}$ \\
Triturador & $75,7 \mathrm{~A}$ & $4,3 \mathrm{~A}$ \\
Herbicida & $75,4 \mathrm{~A}$ & \\
Pressões (P) & $75,0 \mathrm{~A}$ & $4,3 \mathrm{~A}$ \\
75 & $0,7^{\mathrm{ns}}$ & $4,4 \mathrm{~A}$ \\
55 & $1,0^{\mathrm{ns}}$ & $0,9^{\mathrm{ns}}$ \\
\hline Teste F & $1,0^{\mathrm{ns}}$ & $0,2^{\mathrm{ns}}$ \\
M & 12,8 & $2,9^{\mathrm{ns}}$ \\
P & 1,9 & 5,2 \\
MxP & 6,0 \\
\hline C.V. Manejo & & 6,0 \\
C.V. Pressão & & $5 \%$ prabilide.
\end{tabular}

Médias seguidas de mesma letra maiúscula na coluna não diferem entre si, pelo teste de Tukey, a 5\% de probabilidade. C.V.: coeficiente de variação. ${ }^{* *}$ : significativo a $\mathrm{P}<0,01 .{ }^{\text {ns: }}$ : não significativo.

O número de dias para emergência (Tabela 4) resultou em valores médios de 4,0 dias para emergência, sendo considerados valores baixos se comparados aos resultados obtidos por FAGANELLO et al. (1999), em que a emergência atingiu 50\% no sexto dia após a semeadura.

$\mathrm{Na}$ Tabela 5, observa-se que, na distribuição longitudinal de plântulas, nenhum dos fatores testados afetaram os parâmetros (espaçamentos normais, falhos e duplos). Os resultados obtidos para espaçamentos falho, normal e duplo podem ser explicados pelo elevado valor do coeficiente de variação, pois, segundo ANDERSSON (2001), valores ótimos de coeficiente de variação na semeadura estão abaixo de $10 \%$, valores de $10 \%$ a $30 \%$ são considerados regulares e acima de $30 \%$, ruins. O autor considera os coeficientes de variação como índice da eficiência dos mecanismos dosadores. Quando ocorrem muitas falhas, pode causar a diminuição da produtividade, enquanto as plantas próximas (duplos) apresentam produtividade média perto da ideal. Nesse contexto, a desuniformidade da distribuição pode reduzir em até $20 \%$ a produtividade. 
TABELA 5. Síntese da análise de variância para distribuição longitudinal de plântulas de milho nos espaçamentos normal, falhos e duplos para os manejos e pressões de inflação do pneu da semeadora. Variance analysis synthesis for longitudinal distribution of corn seedling in normal, failed and double spaces for management and tire inflation pressure of sowing.

\begin{tabular}{|c|c|c|c|}
\hline \multirow{2}{*}{\multicolumn{4}{|c|}{$\frac{\text { Fatores }}{\text { Manejos (M) }}$}} \\
\hline & & & \\
\hline Rolo-Faca & $87,2 \mathrm{~A}$ & $9,9 \mathrm{~A}$ & $3,2 \mathrm{~A}$ \\
\hline Triturador & $88,8 \mathrm{~A}$ & $8,4 \mathrm{~A}$ & $3,2 \mathrm{~A}$ \\
\hline Herbicida & $86,6 \mathrm{~A}$ & $11,4 \mathrm{~A}$ & $2,1 \mathrm{~A}$ \\
\hline \multicolumn{4}{|l|}{ Pressões (P) } \\
\hline $525 \mathrm{kPa}$ & $88,2 \mathrm{~A}$ & $7,5 \mathrm{~A}$ & $4,6 \mathrm{~A}$ \\
\hline $385 \mathrm{kPa}$ & $86,9 \mathrm{~A}$ & $12,3 \mathrm{~A}$ & $1,0 \mathrm{~A}$ \\
\hline \multicolumn{4}{|l|}{ Teste de F } \\
\hline M & $0,2^{\mathrm{ns}}$ & $0,4^{\mathrm{ns}}$ & $0,1^{\mathrm{ns}}$ \\
\hline $\mathrm{P}$ & $0,1^{\mathrm{ns}}$ & $3,0^{\mathrm{ns}}$ & $3,1^{\mathrm{ns}}$ \\
\hline $\mathrm{MxP}$ & $1,3^{\mathrm{ns}}$ & $1,3^{\mathrm{ns}}$ & $0,6^{\mathrm{ns}}$ \\
\hline C.V. Manejo & 11,8 & 91,4 & 254,2 \\
\hline C.V. Pressão & 13,7 & 96,1 & 254,8 \\
\hline
\end{tabular}

Médias seguidas de mesma letra maiúscula na coluna não diferem entre si, pelo teste de Tukey, a 5\% de probabilidade. C.V.: coeficiente de variação. ${ }^{* *}$ : significativo a $\mathrm{P}<0,01 .{ }^{\text {ns: }}$ : não significativo.

\section{CONCLUSÕES}

O manejo da cultura do sorgo com rolo-faca proporcionou maior capacidade de campo e menor consumo de combustível em relação ao triturador de palhas.

A cobertura do solo, o número de dias para a emergência e a distribuição longitudinal não foram afetados pelos fatores (manejos e pressões de inflação do pneu da semeadora).

\section{REFERÊNCIAS}

ABNT. ASSOCIAÇÃO BRASILEIRA DE NORMAS TÉCNICAS. Semeadora de precisão: ensaio de laboratório/método de ensaio, projeto de norma 12:02.06-004. Rio de Janeiro, 1989. 21 p.

ANDERSSON, C. Avaliação técnica de semeadoras-adubadoras para plantio direto. Plantio Direto, Passo Fundo, n.66, p.28-32, 2001.

CARVALHO, F.T.; PEREIRA, F.A.R.; PERUCHI, M. Manejo químico das plantas daninhas Euphorbia heterophila e Bidens pilosa em sistema de semeadura direto da cultura da soja. Plantas Daninhas, Viçosa, v.21, n.1, p. 145-150, 2003.

CASÃO JUNIOR, R.; FIGUEIREDO, P.R.A.; ARAÚJO, A.G. Desenvolvimento de rolo-faca à tração animal. In: CONGRESSO BRASILEIRO DE ENGENHARIA AGRÍCOLA, 18., 1989, Recife. Anais... Jaboticabal: Sociedade Brasileira de Engenharia Agrícola, 1992. p.52-66.

CHAHIM FILHO, H.C. Distribuição longitudinal de plântulas de milho e demanda energética de semeadora-adubadora em função do manejo da cobertura e profundidade da deposição de adubo. 2005. 41 f. Monografia (Trabalho de Graduação em Agronomia) - Faculdade de Ciências Agrárias e Veterinárias, UNESP, Jaboticabal, 2005.

EDMOND, J.B.; DRAPALA, W.L. The effects of temperature, sand and soil, and acetone on germination of okra seed. Proceedings of the American Society for Horticultural Science, Geneva, v.71, p.428-434, 1958.

EMBRAPA. EMPRESA BRASILEIRA DE PESQUISA AGROPECUÁRIA. Sistema Brasileiro de Classificação de Solos. Rio de Janeiro, 1999. 412 p. 
FAGANELLO, A.; SATTLER, A.; PORTELLA, J.A. Eficiência de semeadoras na emergência de plântulas de milho (Zea mays) sob Sistema Plantio Direto. Plantio Direto, Passo Fundo, n.50, p.2930, 1999.

FURLANI, C.E.A.; GAMERO, C.A.; LEVIEN, R.; LOPES, A. Resistência do solo à penetração em preparo convencional e semeadura direta em diferentes manejos da cobertura vegetal. Engenharia Agrícola, Jaboticabal, v.23, n.3, p.579-587, 2003.

GAMERO, C.A.; SIQUEIRA, R.; LEVIEN, R.; SILVA, S.L. Decomposição da aveia preta (Avena strigosa Schre.) manejada com rolo-faca e triturador de palhas. In: CONGRESSO BRASILEIRO DE ENGENHARIA AGRÍCOLA, 26., 1997, Campina Grande. Anais... Campina Grande: Sociedade Brasileira de Engenharia Agrícola, 1997. 1 CD-ROM.

GERLACH, J.R. Comparação de manejo de sistemas de culturas de cobertura em semeadura direta. 43 f. 2005. Monografia (Trabalho de Graduação em Agronomia) - Faculdade de Ciências Agrárias e Veterinárias, UNESP, Jaboticabal, 2005.

GROTTA, D.C.C. Desempenho de um trator agrícola em operação de gradagem utilizando biodiesel etílico filtrado de óleo residual como combustível. 44 f. 2003. Dissertação (Mestrado em Ciência do Solo) - Faculdade de Ciências Agrárias e Veterinárias, UNESP, Jaboticabal, 2003.

LAFLEN, J.M.; AMEMIYA, A.; HINTZ, E.A. Measuring crop residue cover. Soil and Water Conservation, Ankeny, v.36, n.6, p. 341-343, 1981.

LOPES, A.; FURLANI, C.E.A.; SILVA, R.P. Desenvolvimento de um protótipo para medição do consumo de combustível em tratores. Revista Brasileira de Agroinformática, Lavras, v.5, n.1, p.2431, 2003.

MARQUES, J.P.; LEVIEN, R.; BENEZ, S.H. Desempenho operacional de um escarificador em solo sob vegetação espontânea diferentemente manejada. In: CONGRESSO BRASILEIRO DE ENGENHARIA AGRÍCOLA, 28., 1999, Pelotas. Anais... Pelotas: Sociedade Brasileira de Engenharia Agrícola, 1999. 1 CD-ROM.

MERTEN, G.H.; FERNANDES, F.F. Manejo do solo e baixa aptidão. In: DAROLT, M.R. (Coord.). Plantio Direto: pequena propriedade sustentável. Londrina: IAPAR, 1998. p.1-17. (Circular, 101).

MONTEIRO FILHO, J. A. Manejo da vegetação de cobertura e população de plantas de milho (Zea mays L.) no desempenho da semeadora-adubadora em Sistema Plantio Direto. 2005. 57 f. Monografia (Trabalho de Graduação em Agronomia) - Faculdade de Ciências Agrárias e Veterinárias, Universidade Estadual Paulista, Jaboticabal, 2005.

PRADO, R.M.; NATALE, W.; FURLANI, C.E.A. Manejo mecanizado de atividades para a implantação de culturas. Jaboticabal: Sociedade Brasileira de Engenharia Agrícola, 2002. 99 p.

REIS, G.N.; FURLANI, C.E.A.; SILVA, R.P.; GERLACK, J.R.; CORTEZ, J.W.; GROTTA, D.C.C. Decomposição de culturas de cobertura no sistema plantio direto, manejadas mecânica e quimicamente. Engenharia Agrícola, Jaboticabal, v.27, n.1, p.194-200, 2007.

VIEIRA, L.B.; REIS, E.F. Máquinas para o plantio direto. Informe Agropecuário, Belo Horizonte, v.22, n.208, p.44, 2001.

YAMAOAKA, R.S. Equipamentos. In: SIMPÓSIO SOBRE ENERGIA NA AGRICULTURA, 1., 1984, Jaboticabal. Anais... Jaboticabal: Faculdade de Ciências Agrárias e Veterinárias, 1984. p.81. 